\title{
doi.org/10.46291/ISPECIJSSHvol4iss4pp328-342
}

\section{Üniversitelerin İş Sağlığı ve Güvenliği Programında Görev Yapan Akademisyenler Üzerine Bir İnceleme}

\section{Berna GÜR}

Şenol YAVUZ

Dr. Öğr. Üyesi, Hitit Üniversitesi, Teknik Bilimler Meslek Yüksekokulu, Mülkiyet Koruma ve Güvenlik Bölümü, Çorum. bernagur@ hitit.edu.tr; 0000-0002-0674-4612

Dr. Öğr. Üyesi, Hitit Üniversitesi, Osmancık Ömer Derindere Meslek Yüksekokulu, Mülkiyet Koruma ve Güvenlik Bölümü, Osmancık, Çorum. senolyavuz@ hitit.edu.tr, 0000-0001-62619296

\section{ÖZET}

İş Sağlığı ve Güvenliği hayatımızın her aşamasında yer almaktadır. İlk aklımıza gelen işletmelerde çalışanların sağlığının korunması ve güvenli bir çalışma ortamının sağlanılması şeklinde düşünülebilir. İş sağlığı ve güvenliğinin amacı; iş kazası ve meslek hastalıklarının önlenmesi, çalışanların sosyal, ruhsal ve bedensel olarak tam iyilik halinin sağlanmasıdır. Ayrıca, üniversitelerde iş sağlığı ve güvenliği dersinin müfredata eklenmesi ile iş sağlı̆̆ı ve güvenliği bilincinin kazanılması amaçlanmıștır. Zaman içerisinde İş Sağlığı ve Güvenliği alanında profesyonellere ihtiyaç duyularak İSG Uzmanlığı mesleği ortaya çıkmıştır. Üniversitelerde, önlisans ve lisansda İş Sağlığı ve Güvenliği programı açılarak sektörün ihtiyacı olan uzman ihtiyacının giderilmesi hedeflenmiştir. Programların kuruluşlarında alanından yetişmiş hoca olmadığından, fizik, kimya, biyoloji, mühendislik fakülteleri ve teknik eğitim fakültelerinde bulunan akademisyenler derse girmiştir. Zaman içerisinde İSG uzmanlığı ya da İSG eğitici belgesine sahip hocalar derse girerek, yüksek lisans ve doktora ile alanında yetişmiş akademisyenler yetişmeye başlanmıştır. Günümüzde alanında yetkin hocaların sayısı azdır. Belirli bir uzmanlık alanı hala yoktur. Bu çalışmada, Üniversitelerde İSG eğitimi veren akademisyenlerin İSG alanındaki akademik kariyerlerini, uzmanlık alanlarını, demografik yapılarını, bu alanda akademik kariyerlerine devam etmek isteyip istemediklerini incelemek üzerine yapılmış bir çalışmadır. Elde edilen veriler "IBM SPSS Statistics 22.0" programı ile analiz edildi. "Cronbach Alpha $(\alpha)$ " değeri 0.623 bulunarak çalışmanın güvenirliği sağlanmış oldu. Erkek, evli, C sınıfı belgesi, öğretim görevlisi akademisyenlerin çoğunlukta olduğunu görüyoruz. Ankete katılanların İş Sağlığı ve Güvenliği alanında doçent ünvanı almak istediklerini, İSG Programının mühendislik fakültesinde olması gerektiğini düşündüklerini görüyoruz. Sonuç olarak; İş Güvenliği alanında akademik çalışma yapan hocaların azınlıkta olduğunu görüyoruz. Bu sonuçlara göre İş Sağlığı ve Güvenliği alanında doçent ve prof ünvanına sahip hocaların yetişmesinin zaman alacağını söyleyebiliriz.

Anahtar kelimeler: Akademisyen, İSG Programı, İş Güvenliği Uzmanı 


\title{
An Investigation on Academists Dutting in the Occupational Health and Safety Program of Universities
}

\begin{abstract}
Occupational Health and Safety is at every stage of our life. It can be considered as protecting the health of employees and providing a safe working environment in the businesses that come to our mind. The purpose of occupational health and safety; Prevention of work accidents and occupational diseases is to ensure the full social, mental and physical well-being of the employees. In addition, it is aimed to gain occupational health and safety awareness by adding the occupational health and safety course to the curriculum in universities. OHS Specialist profession has emerged with the need of professionals in the field of Occupational Health and Safety over time. At the universities, the Occupational Health and Safety program is opened in associate and undergraduate degrees, and it is aimed to meet the needs of experts in the sector. Academicians in physics, chemistry, biology, engineering faculties and technical education faculties attended the course since there were no trained professors in the establishment of the programs. Over time, teachers who have the OHS expertise or OHS trainer certificate have entered the course and the academics trained in the field have started to be trained with a master's and a doctorate. Today, the number of proficient teachers is low. There is still no specific specialty. In this study, it is a study to examine the academic careers, specialties, demographic structures and whether they want to continue their academic careers in the field of OHS by academicians who provide OHS education at universities. The data obtained were analyzed with the "IBM SPSS Statistics 22.0" program. The reliability of the study was provided by finding the value of "Cronbach Alpha $(\alpha)$ " 0.623 . We see that the majority of academicians are male, married, $\mathrm{C}$ class certificate, lecturers. We see that the respondents want to get the title of associate professor in the field of Occupational Health and Safety and think that the OHS Program should be in the engineering faculty. As a result; We see that there are a few of the teachers working in the field of Occupational Safety. According to these results, we can say that it will take time to train professors and professors in the field of Occupational Health and Safety.
\end{abstract}

Keywords: Academician, OHS Program, Occupational Safety Specialist

\section{GíRiş}

İSG tanım olarak, "işyerlerinde işin yürütülmesi esnasında çeşitli nedenlerden kaynaklanan sağllğa zarar verebilecek sebeplerden korunmak amacıyla yapılan sistemli ve bilimsel çalışmalardır." İSG kavramı, 1989 yılında yürürlüğe giren 89/391/EEC sayılı İş Sağlı̆̆ı ve Güvenliği Direktifi ile iş sağlığı ve güvenliği alanında temel bir direktif olarak kabul görmüş ve daha sonraları bu temel direktife dayanarak pek çok direktif çıkarılmıştır. 2012 yılında 6331 sayılı İSG Kanunun girmesiyle de ülkemizde $A B$ ile uyum süreci başlamış ve hızlanmaya devam etmiştir ( Kılkış, 2013).

Year 4/ 2020, Volume-4, Issue-4 | WWW.ispecjournal.org 


\section{İSG' nin Amacı;}

Herhangi Bir İşletmede Çalışanların Güvenliğini Sağlamak: İş sağlı̆̆ı ve güvenliğinin en temel amacı çalışanların güvenliğini sağlamaktır. Çalışanları tehlike ve risklerden kaynaklanan iş kazaları ve meslek hastalıklarına karşı koruyarak ruh ve beden bütünlüklerinin bozulmamasını sağlamaktadır.

Üretimin daha Güvenli olmasını Sağlamak: Bir işletmede üretimin güvenliğinin sağlanması ile verim artmaktadır. Verimin artması ile işletmenin kar yüzdesi giderek artmaya başlar.

İşletmenin Güvenliğini Devam Ettirmek: İşletmede alınacak önlemlerle, çalışanın ruh ve beden sağlığını etkileyen iş kazalarından, makine arızalarından ve patlama, yangın olaylarından kaynaklanan işletmeyi tehlikeye düşürebilecek her türlü durumlar ortadan kaldırılacak işletme güvenliği ve üretimin devamlılığı sağlanmış olur (Bıyıkc1, 2010).

İş sağlığı ve güvenliği bütün iş kollarını kapsayan hem çalışanın sağlığı hem de işletmenin güvenli bir şekilde üretime devam etmesini sağlayan sistematik çalışmaların tamamıdır. İş sağlığı ve güvenliği uygulanırken tıp, fizik, kimya, matematik bilimlerden faydalanılır. İş sağlığı ve iş güvenliği konusunda yapılan bütün çalışmalara rağmen, iş kazaları ve meslek hastalıklarını beklenilen oran elde edilememiştir. İş kazaları ile meslek hastalıklarında aynı oranda artış görülememiştir. Tüm iş kollarında meslek hastalığı meydana gelir (Gür ve Sezik, 2020). Elde edilen iş kazaları verilerine göre, yaralanmalar, deri hastalıkları, elektrik çarpması, eklem rahatsızlıkları, kırıklar, uzuv kayıpları, ölümler şeklinde görülmektedir. İş sağlığı ve iş güvenliğinin amacı çalışanı koruma, üretimin devamlılığ 1 ve işletmenin güvenliğini sağlayıcı proaktif yaklaşımların tümüdür (Arslan, 2014).

İSG uzmanlığında 3 belge sınıfı bulunmaktadır. Bunlar A, B, C sınıfı olmak üzere üçe ayrılmıştır. Bunlar;

A sınıfı belgesine sahip olan uzmanlar; az tehlikeli, tehlikeli ve çok tehlikeli işletmelerde,

B sınıfı belgesine sahip olan uzmanlar; az tehlikeli ve tehlikeli işletmelerde,

C sınıfı belgesine sahip olan uzmanlar; az tehlikeli işletmelerde çalışabilirler (Orhan, 2014).

Ülkemizde kişilerin bu belgelere sahip olabilmeleri için çeşitli eğitimler verilmektedir. $\mathrm{Bu}$ eğitimler üniversitelerde ya da bakanlık tarafından yetkilendirilmiş eğitim kurumlarınca verilmektedir(Doğan vd. 2017). Üniversitelerde ön lisans, lisans, yüksek lisans ve doktora derecelerinde İSG eğitimi verilirken, bakanlık tarafından yetkilendirilmiş eğitim kurumlarınca 
yine bakanlığın uygun gördüğü fakültelerden mezun olan kişiler İSG eğitimi alarak C sınıfı belgeye sahip olabilirler (Sivrikaya, 2016).

Şekil 1. Türkiye'de iş sağlığı ve güvenliği uzmanlığı belgesini alabilmek için başlıca eğitim seçenekleri (Sivrikaya, 2016).

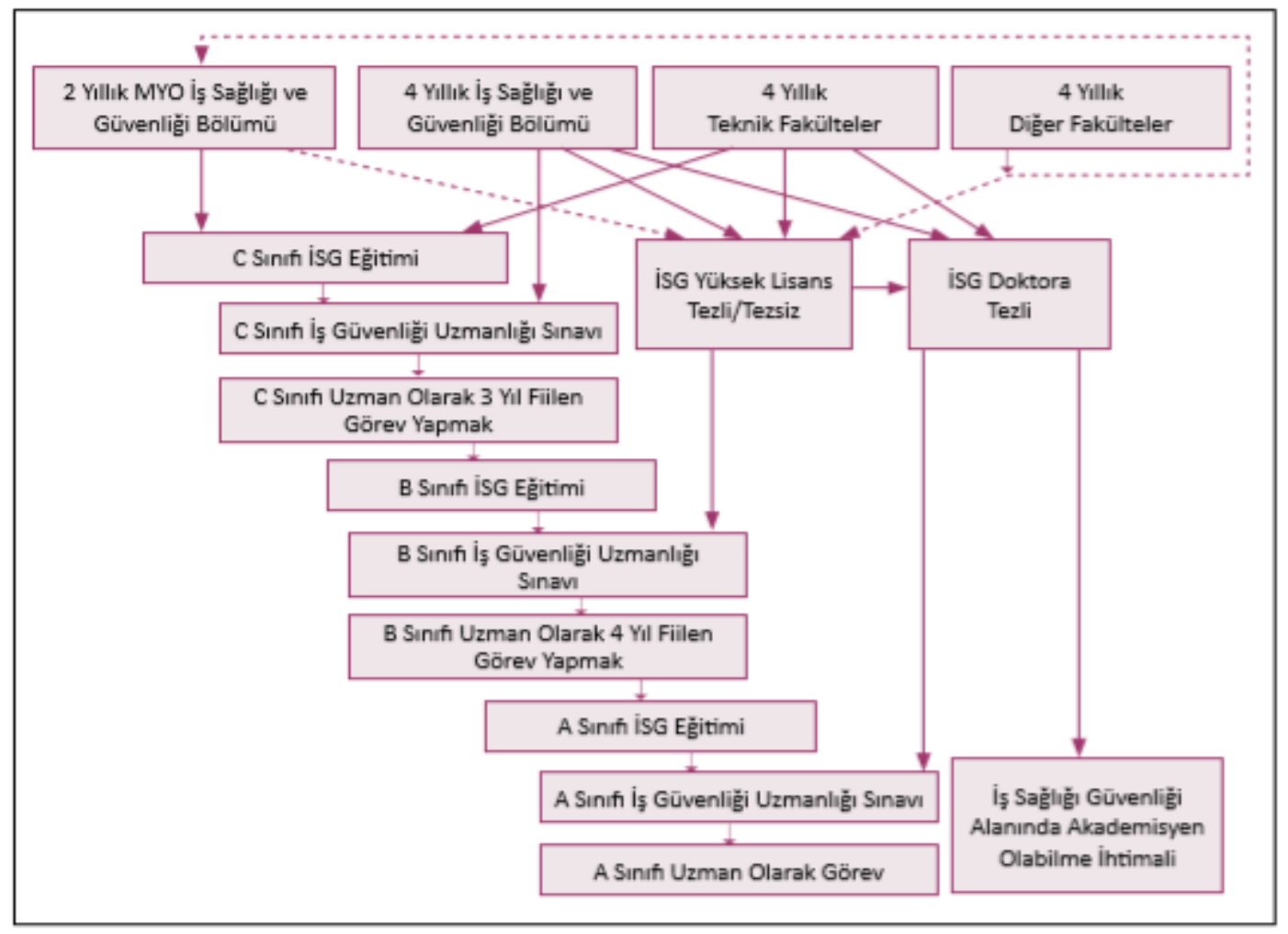

İş sağlı̆̆ı ve güvenliği eğitimde İSG hocalarının yeri çok önemlidir. İyi bir İSG eğitimi, eğiticinin kalitesiyle doğru orantılı olmaktadır. Meslek yüksekokullarında İSG programlarında bulunan öğretim elemanlarıyla ilgili bazı eksiklikler mevcuttur. Bunlar;

> Öğretim elemanlarının sayı bakımından yeterli olmayışı,

> İSG alanı dışında görev yapan öğretim elemanlarının İSG bölümlerinde derse girmesi,

> Akademsiyenlerin, İş Sağlığı ve Güvenliği alanında saha tecrübelerinin az oluşu,

> İSG programlarında görev yapan hocaların İSG dışındaki uzmanlık alanlarıyla ilgili lisansüstü eğitime ve araştırmalara daha çok yönelmeleri,

İş sağlığı ve güvenliği bölümlerinde yeterli sayıda öğretim elemanı bulunmamaktadır. Bazı meslek yükssekokullarında İSG alanında yetkin olmayan, uzmanlık ya da eğitici belgesine sahip olmayan öğretim elemanları mevcuttur. Öğretim elemanlarıyla ilgili diğer bir eksiklik ise farklı alanlardan mezun olan akademisyenlerin İş Sağlı̆̆ı ve Güvenliği programlarında görev yapmalarıdır. Meslek yüksekokullarına bakıldığı zaman işletme, halkla ilişkiler gibi Year 4/ 2020, Volume-4, Issue-4 | WWW.ispecjournal.org 
İSG ile alakası olmayan pek çok akademisyenin İSG bölümlerinde kadrosu olduğu görülmektedir. Bu bölüme atanan akademisyenlerin İSG alanında çalışmalarına devam edebilmeleri için İş sağlığı ve güveliği bölümlerinde yüksek lisans ve doktora programlarının artırılması gerekmektedir. Ayrıca bu alanda görev yapan akademisyenlerin mağdur olmamaları için YÖK tarafından iş sağlığı ve güveliği alanında doçentlik unvanı verilmelidir (Ceylan, 2012).

İş sağlığı ve güvenliği önlisans/lisan bölümlerinin amacı, iş hayatında meydana gelme ihtimali olan iş kazaları, meslek hastalıkları ve ramak kalalar ile ilgili olarak güncel veriler doğrultusunda çalışma hayatında; analitik ve mühendislik olarak düşünebilen, uzman İSG profesyonelleri yetiştirmek, iş sağlığı ve güvenliği ile ilgili yasal mevzuatı öğrenen, güncel gelişmelere ayak uyduran, yorumlayan ve mesleki ahlak kurallara uyan, iş kazası ve meslek hastalıkları olması durumunda risk değerlendirme prosedürlerine bağlı olarak iş güvenliğinin uygulanabilmesi için tüm tedbirleri alabilecek yetkinlikte bireyler yetiştirme gayesi ile kurulmuştur. $\mathrm{Bu}$ şekilde, mezun olan öğrenciler özel sektörde geniş bir istihdam firsatı olanağ1 sağlanmış olacaktır. Mezun olan öğrencilere "İş Sağlığı ve Güvenliği Teknikerliği" ünvanı ile önlisans diploması verilir. Mezunlar daha sonra T.C. Aile, Çalışma ve Sosyal Hizmetler Bakanlığg’nın yaptığı “ $\mathrm{C}$ ” sınıfı iş güvenliği uzmanlığı sınavına girebilirler (Şensöğüt, 2018).

İSG bölümlerinin misyonu, iş hayatında yaşanabilecek iş kazaları ve meslek hastalıklarına karşı hazırlıklı olma; işvereni, çalışanı ve üretimi olumsuz etkileyen risklerin neden oldukları zararları azaltarak ülke ekonomisine katkıda bulunma; mesleki bilgi ve becerileri kazanmış, iletişimi kuvvetli, donanımlı, değişim ve yeniliklere açık, İSG Uzmanının önemini kavramış, İSG bilincinde, bilim ve teknolojideki değişimlere ayak uyduran, insanlarla iletişimi seven, saygılı, nitelikli, İş Sağlığı ve Güvenliği Uzmanlarını topluma kazandırmaktır (Aksoy vd. 2013).

Bu çalışma da; Üniversitelerde İSG eğitimi veren akademisyenlerin İSG alanındaki akademik kariyerleri üzerinde hangi durumların etkili olduğunun bulunması amaçlanmaktadır. Bu ana amaç altında şu hipotezler belirlenmiştir.

H1- Üniversitelerde İSG eğitimi veren akademisyenlerin demografik özelliklerine göre İSG alanındaki akademik kariyerlerinde farklılıklar vardır. 
H2- Üniversitelerde İSG eğitimi veren akademisyenlerin İSG alanında doçent olma istekleri ile alanla ilgili lisansüstü eğitim görmeleri arasında anlamlı farklılıklar vardır.

H3- Üniversitelerde İSG eğitimi veren akademisyenlerin İSG alanında doçent olma istekleri ile alanla ilgili yayın sayıları arasında anlamlı farklılıklar vardır.

\section{YÖNTEM}

\section{Evren ve Örneklem}

Araştırmanın evrenini üniversitelerde İSG derslerine giren 180 kişi oluşturmaktadır. Çalışmanın örneklemini ankete gönüllü olarak katılan ve üniversitelerde İSG derslerine giren 60 akademisyen oluşturmaktadır. Araştırma, Üniversitelerde İSG eğitimi veren akademisyenlerin uygulanan anket maddelerine kendi özgür iradeleriyle ve objektif olarak yanıt verdiklerini varsayarak gerçekleştirilmiştir.

Araştırmada verileri elde etmek için anket yönteminden yararlanılmıştır. Araştırma veriler için hazırlanan anket 2 bölümden oluşmaktadır. Birinci bölümde demografik bilgilere ait 10 soru, ikinci bölümde ise İSG alanındaki akademik kariyer yönelimlerini belirlemek için 12 soru sorulmuştur.

\section{BULGULAR}

Anket sorularına verilen cevaplar "IBM SPSS Statistics 22.0" programı ile analiz edildiğinde “Cronbach Alpha ( $\alpha$ )" değeri 0.623 bulunmuştur. Bulunan değerin $0.6<\alpha<0.8$ aralığında olması araştırmanın güvenilirliğini kanıtlamaktadır. Demografik özellikler için frekanslar ve yüzdeler bulunmuş. Hipotezlerin doğruluğunu test etmek için Dörtlü Korelesyon Cramer analizi, Mann Whitney U analizi ve Kruskal-Wallis analizleri yapılarak yorumlanmıştır. Yapılan anket çalışmamızın sonuçlarının birbiriyle tutarlı ve anlaşılır olması Üniversitelerde İSG eğitimi veren akademisyenlerin anketi doğru anladığını göstermektedir. Araştırmada $\mathrm{p}<0.05$ değeri anlamlı farkı ifade etmektedir.

\begin{tabular}{|lll|}
\hline Cinsiyet & $\mathbf{N}$ & $\mathbf{\%}$ \\
\hline Erkek & 33 & 55 \\
\hline Kadın & 27 & 45 \\
\hline Medeni Durum & $\mathbf{N}$ & $\mathbf{\%}$ \\
\hline Evli & 38 & 63.3 \\
\hline Bekâr & 22 & 36.7 \\
\hline Yaş & $\mathbf{N}$ & $\mathbf{\%}$ \\
\hline $20-29$ & 5 & 8.3 \\
\hline
\end{tabular}


ISSN 2717-7262 ISPEC Journal of Social Sciences \& Humanities

\begin{tabular}{|c|c|c|}
\hline $30-39$ & 35 & 58.3 \\
\hline $40-49$ & 15 & 25,0 \\
\hline $50 \mathrm{Ve}$ Üstü & 5 & 8.3 \\
\hline Uzmanlık Belgesi & $\mathbf{N}$ & $\%$ \\
\hline A & 7 & 11.7 \\
\hline B & 15 & 25.0 \\
\hline $\mathrm{C}$ & 29 & 48.3 \\
\hline Yok & 9 & 15 \\
\hline Ĕgitim Düzeyiniz & $\mathbf{N}$ & $\%$ \\
\hline Yüksek Lisans & 24 & 40 \\
\hline Doktora & 36 & 60 \\
\hline Kadro & $\mathbf{N}$ & $\%$ \\
\hline Araştırma Gör. & 2 & 3.3 \\
\hline Öğr. Gör. & 33 & 55.0 \\
\hline Dr. Öğr. Üyesi & 20 & 33.3 \\
\hline Doçent & 4 & 6.7 \\
\hline Prof. Dr. & 1 & 1.7 \\
\hline Görev Yapılan Üniversitede & $\mathbf{N}$ & $\%$ \\
\hline Devlet & 41 & 68.3 \\
\hline Vakıf & 19 & 31.7 \\
\hline Mezun Olunan Fakülte & $\mathbf{N}$ & $\%$ \\
\hline İsg & 4 & 6.7 \\
\hline Fen & 19 & 31.7 \\
\hline Mühendislik & 31 & 51.7 \\
\hline Diğer & 6 & 10.0 \\
\hline Görev Yapılan Birim & $\mathbf{N}$ & $\%$ \\
\hline Мyo & 41 & 68.3 \\
\hline Sağlık Hizmetleri & 13 & 21.7 \\
\hline Fen Fakültesi & 6 & 10 \\
\hline $\begin{array}{l}\text { İsg Bölümünde } \\
\text { Çalışma Süresi }\end{array}$ & $\mathbf{N}$ & $\%$ \\
\hline Yok & 2 & 3.3 \\
\hline 1-2 Y11 & 18 & 30.0 \\
\hline 3-5 Y1l & 28 & 46.7 \\
\hline 6-9 Y11 & 8 & 13.3 \\
\hline 10 Yil ve üzeri & 4 & 6.7 \\
\hline
\end{tabular}

Üniversitelerde İSG eğitimi veren akademisyenlerin demografik özelliklerinin (yaş, cinsiyet, medeni durum, uzmanlık belgesi, eğitim düzeyi, kadro ünvanları, görev yapılan üniversite, mezun olunan fakülte, görev yapılan birim, İSG bölümünde çalışma süresi) dağılımları tablo halinde verilmiştir. 
Tablo 1 verilerine göre 33 erkek ve 27 kadın olmak üzere toplam 60 kişi katılmıştır. Akademisyenlerden 5 kişi 20-29 yaşları arasında, 35 kişi 30-39 yaşları arasında, 15 kişi 40-49 yaşları arasında ve 5 kişi 50 yaş ve üzerinde yaşları arasındadır. Ankete katılanlardan 38 kişi evli iken 22 kişi bekârdır. Çalışanların eğitim düzeylerine bakıldığında 24 kişi yüksek lisans, 36 kişi ise doktora mezunudur. İSG bölümünde ders veren akademisyenlerden ikisinin iş güvenliği uzmanlık belgesi yok iken, 29 kişi C sınıfı, 15 kişi $\mathrm{B}$ sınıfı ve 7 kişi A sınıfı iş güvenliği uzmanlık belgesine sahiptir. Akademisyenlerin 2 kişisi araştırma görevlisi, 33 kişisi Öğr. Gör., 20 kişi Dr. Öğr. Üyesi, 4 kişi doçent ve 1 kişi Prof. Dr. Olarak görev yapmaktadır. Akademisyenlerden 41 kişi devlet üniversitesinde, 19 kişi vakıf üniversitesinde çalışmaktadır. Ankete katılan 61 akademisyenin 41'i MYO, 13'ü Sağlık hizmetleri, 6's1 fen fakültesinde görev yapmaktadır. Akademisyenlerden 18 kişi 1-2 yıl, 28 kişi 3-5 yıl, 8 kişi 6-9 yıl, 4 kişi 10 yıl ve üzeri görev yaparken, 2 kişi bu bölümde görev yapmamıştır. Ankete katılan öğretim elemanın 31 kişi mühendislik fakültesi, 19 kişi fen fakültesi, 6 kişi diğer fakültelerden, 4 kişi ise İSG bölümü mezunudur.

Tablo 2: Tamamlayıcı İstatistik Veriler

\begin{tabular}{|c|c|c|}
\hline İsg'de Yüksek Lisans & $\mathbf{N}$ & $\%$ \\
\hline Evet & 20 & 33.3 \\
\hline Hayır & 40 & 66.7 \\
\hline İsg'de Doktora & $\mathbf{N}$ & $\%$ \\
\hline Evet & 10 & 16.7 \\
\hline Hayır & 50 & 83.3 \\
\hline İsg Alanında Scı'lı Yayın Sayısı & $\mathbf{N}$ & $\%$ \\
\hline Yok & 55 & 91.7 \\
\hline $1-2$ & 5 & 8.3 \\
\hline $\begin{array}{l}\text { İsg Alanında Diğer Uluslararası } \\
\text { İndeksli Yayın Sayısı }\end{array}$ & $\mathbf{N}$ & $\%$ \\
\hline Yok & 40 & 66.7 \\
\hline $1-3$ & 13 & 21.7 \\
\hline $4-7$ & 5 & 8.3 \\
\hline $8-10$ & 2 & 3.3 \\
\hline $\begin{array}{l}\text { Uluslararası Kitap Bölüm } \\
\text { Yazarlığı }\end{array}$ & $\mathbf{N}$ & $\%$ \\
\hline Yok & 50 & 83.3 \\
\hline $1-3$ & 7 & 11.7 \\
\hline $4-7$ & 3 & 5.0 \\
\hline $\begin{array}{l}\text { İsg Alanında Ulusal İndeksli } \\
\text { Yayın Sayısı }\end{array}$ & $\overline{\mathbf{N}}$ & $\%$ \\
\hline Yok & 34 & 56.7 \\
\hline
\end{tabular}




\begin{tabular}{|lll|}
\hline $1-2$ & 22 & 36.7 \\
\hline $3-4$ & 1 & 1.7 \\
\hline $5-6$ & 3 & 5.0 \\
\hline Ulusal Kitap Yazarlı̆̆ı & $\mathbf{N}$ & $\mathbf{\%}$ \\
\hline Yok & 59 & 98.3 \\
\hline $1-3$ & 1 & 1.7 \\
\hline Ulusal Kitap Bölüm Yazarlı̆̆ & $\mathbf{N}$ & $\mathbf{\%}$ \\
\hline Yok & 54 & 90.0 \\
\hline $1-3$ & 5 & 8.3 \\
\hline 3 Ve Üzeri & 1 & 1.7 \\
\hline Uluslararası Kongre Sayısı & $\mathbf{N}$ & $\mathbf{\%}$ \\
\hline Yok & 23 & 38.3 \\
\hline $1-3$ & 25 & 41.7 \\
\hline $4-7$ & 8 & 13.3 \\
\hline 8 Ve Üzeri & 4 & 6.7 \\
\hline Ulusal Kongre Sayısı & $\mathbf{N}$ & $\mathbf{\%}$ \\
\hline Yok & 32 & 53.3 \\
\hline $1-3$ & 21 & 35.0 \\
\hline 4 Ve Üzeri & 7 & 11.7 \\
\hline İsg'de Doçentlik Alma İsteği & $\mathbf{N}$ & $\mathbf{\%}$ \\
\hline Evet & 39 & 65.0 \\
\hline Hayır & 21 & 35.0 \\
\hline İsg Hangi Fakültede Olmalı & $\mathbf{N}$ & $\mathbf{\%}$ \\
\hline Mühendislik & 37 & 61.7 \\
\hline Sağlık & 10 & 16.7 \\
\hline Sosyal & 3 & 5.0 \\
\hline Fen & 8 & 13.3 \\
\hline Diğer & 2 & 3.3 \\
\hline & & \\
\hline & & \\
\hline
\end{tabular}

Tablo 3: Dörtlü Korelasyon Cramer Katsayısı Analizi

\begin{tabular}{|c|c|c|c|c|}
\hline & \multicolumn{2}{|c|}{ İSG alanında akademik kariyer isteği } & $\varnothing$ & $\mathbf{p}$ \\
\hline Cinsiyet & Evet & Hayır & \multirow{3}{*}{.109} & \multirow{3}{*}{.399} \\
\hline Erkek & 23 & 10 & & \\
\hline \multirow[t]{2}{*}{ Kadın } & 16 & 11 & & \\
\hline & \multicolumn{2}{|c|}{ İSG alanında akademik kariyer isteği } & $\bar{\emptyset}$ & $\mathbf{p}$ \\
\hline Medeni durum & Evet & Hayır & & \\
\hline Evli & 24 & 14 & -.051 & .694 \\
\hline \multirow[t]{2}{*}{ Bekâr } & 15 & 7 & & \\
\hline & \multicolumn{2}{|c|}{ İSG alanında akademik kariyer isteği } & $\varnothing$ & $\mathbf{p}$ \\
\hline $\begin{array}{l}\text { Görev yapılan } \\
\text { üniversite }\end{array}$ & Evet & Hayır & & \\
\hline Devlet & 22 & 19 & -.349 & .007 \\
\hline \multirow[t]{2}{*}{ Vakıf } & 17 & 2 & & \\
\hline & \multicolumn{2}{|c|}{ İSG alanında akademik kariyer isteği } & $\varnothing$ & $\mathbf{p}$ \\
\hline
\end{tabular}

Year 4/ 2020, Volume-4, Issue-4 | WWW.ispecjournal.org 


\begin{tabular}{|c|c|c|c|c|}
\hline Ĕgitim düzeyi & Evet & Hayır & \multirow{3}{*}{.243} & \multirow{3}{*}{.06} \\
\hline Yüksek lisans & 19 & 5 & & \\
\hline Doktora & 20 & 16 & & \\
\hline
\end{tabular}

Akademisyenlerin İSG alanında akademik kariyer istekleri ile cinsiyet, medeni durum, görev yaptıkları üniversite, eğitim düzeyleri arasında anlamlı ilişki olup olmadığını tespit etmek için homojenlik testi yapılmıştır. Yapılan homojenlik testi sonucunda verilen gruplar arasında homojen dağılım olmadığı görülmüş ve anlamlılık ilişkilerinin varlığını belirlemek için dörtlü (Ø) Korelasyon Cramer katsayı (parametrik olmayan) analizleri yapılmıştır. Analiz sonucunda sırasıly; $\varnothing=.109 ; \mathrm{p}=.399 ; \varnothing=-.051 ; \mathrm{p}=.694 ; \varnothing=-.349 ; \mathrm{p}=.007^{*} ; \varnothing=.243 ; \mathrm{p}=.06$ sonuçları elde edilmiştir. Dört analiz sonucunda sadece akademik personelin görev yaptıkları üniversite ile İSG alanında akademik kariyer istekleri arasında anlamlı ilişki $(\mathrm{p}<.05)$ olduğu tespit edilmiştir.

Tablo 4: Kruskal-Wallis analiz sonuçları

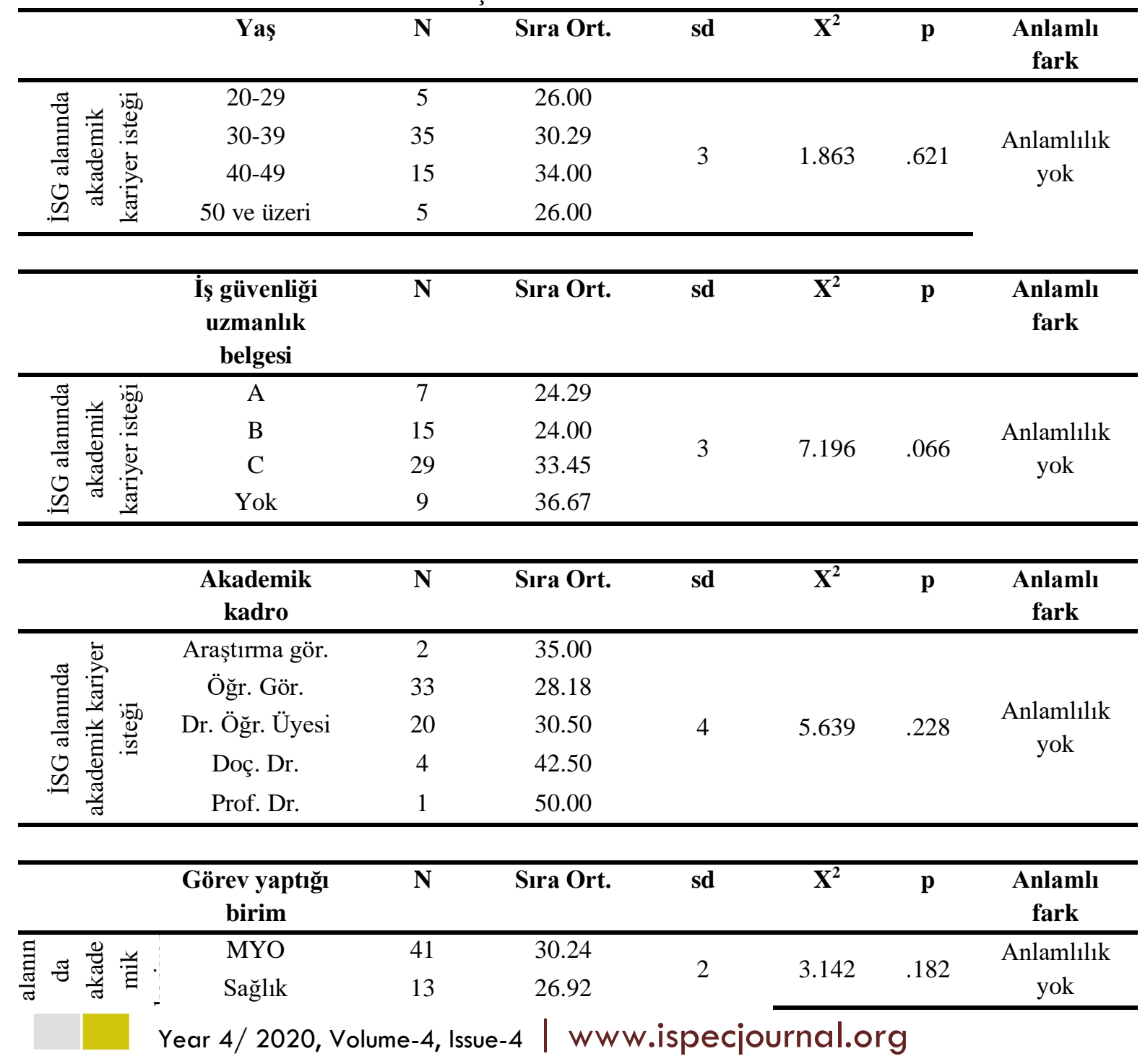




\begin{tabular}{|c|c|c|c|c|c|c|c|}
\hline & $\begin{array}{l}\text { hizmetleri } \\
\text { Fen fakültesi }\end{array}$ & 6 & 40.00 & & & & \\
\hline & $\begin{array}{c}\text { Bölümde } \\
\text { çalışma süresi }\end{array}$ & $\mathbf{N}$ & Sira Ort. & $\overline{\text { sd }}$ & $\overline{X^{2}}$ & $\overline{\mathbf{p}}$ & $\begin{array}{c}\text { Anlamlı } \\
\text { fark }\end{array}$ \\
\hline \multirow{5}{*}{ 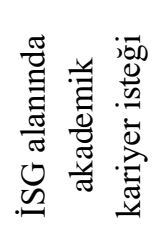 } & Yok & 2 & 50.00 & \multirow{5}{*}{4} & \multirow{5}{*}{8.290} & \multirow{5}{*}{.082} & \multirow{5}{*}{$\begin{array}{c}\text { Anlamlı fark } \\
\text { yok }\end{array}$} \\
\hline & $1-2$ y1l & 18 & 30.00 & & & & \\
\hline & $3-5$ y1l & 28 & 39.64 & & & & \\
\hline & 6-9 y1l & 8 & 23.75 & & & & \\
\hline & 10 yıl ve üzeri & 4 & 42.50 & & & & \\
\hline
\end{tabular}

İSG alanında yetiştirilen öğrencilerin niteliğinin en belirleyici etkenlerinden biri olan İş sağlığı ve güvenliği eğiticilerinin olduğu aşikârdır. Eğiticilerin İSG alanında kendilerini yetiştirmeleri öğrencilerin de eğitim ve niteliğini artıracaktır. Araştırmaya katılan akademisyenlerin yaşa, sahip oldukları iş güvenliği uzmanlık belgesine, akademik unvan, görev yaptığı birim ve bölümde çalışma sürelerine bağlı olarak İSG alanında akademik kariyer isteğinde farklılık olup olmadığı belirlenmek istendi. Verilen gruplar arasında homojenliğin sağlanmadığı için Kruskal-Wallis testi ile anlamlılık testi yapılmıştır. Elde edilen Kruskal-Wallis test sonuçlarında $x^{2}(3, \mathrm{n}=60)=1.863 ; \quad p=.621 ; \quad x^{2}(3, \mathrm{n}=60)=7.196$; $p=.066 ; x^{2}(4, \mathrm{n}=60)=5.639 ; p=.228 ; x^{2}(2, \mathrm{n}=60)=3.142 ; p=.182$ ve $x^{2}(4, \mathrm{n}=60)=8.290 ; p=.082$ verileri elde edilmiştir. Yapılan bu beş testte p değerleri 0.05 den büyük olduğu için akademisyenlerin yaşa, iş güvenliği uzmanlık belgesine, akademik unvan, görev yaptıkları birim ve bölümde çalışma sürelerine bağlı olarak İSG alanında kariyer yapma isteklerinin anlamlı bir farklılık göstermediği belirlenmiştir.

Tablo 5: Mann Whitney analiz sonuçları

\begin{tabular}{|c|c|c|c|c|c|c|c|}
\hline 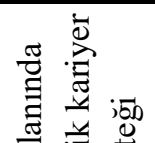 & $\begin{array}{l}\text { Yüksek } \\
\text { lisans } \\
\text { yapma }\end{array}$ & $\mathbf{N}$ & $\begin{array}{l}\text { Sira } \\
\text { Toplamı }\end{array}$ & $\begin{array}{l}\text { Sira } \\
\text { Ortalaması }\end{array}$ & $\mathbf{U}$ & $\mathbf{z}$ & $\mathbf{p}$ \\
\hline 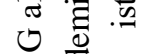 & Evet & 20 & 460.00 & 23.00 & \multirow{2}{*}{250.000} & \multirow{2}{*}{-2.847} & \multirow{2}{*}{.004} \\
\hline$\therefore \frac{\widetilde{E}}{\tilde{E}}$ & Hayır & 40 & 1370.00 & 34.25 & & & \\
\hline \multirow{3}{*}{ 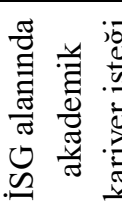 } & $\begin{array}{l}\text { Doktora } \\
\text { yapma }\end{array}$ & $\mathbf{N}$ & $\begin{array}{l}\text { Sira } \\
\text { Toplamı }\end{array}$ & $\begin{array}{l}\text { Sira } \\
\text { Ortalaması }\end{array}$ & $\mathbf{U}$ & $\mathbf{z}$ & $\mathbf{p}$ \\
\hline & Evet & 10 & 230.00 & 23.00 & \multirow[t]{2}{*}{175.000} & \multirow[t]{2}{*}{-1.800} & \multirow[t]{2}{*}{.072} \\
\hline & Hayır & 50 & 1600.00 & 32.00 & & & \\
\hline \multirow{3}{*}{ 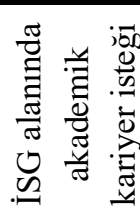 } & $\begin{array}{l}\text { Scı indeksli } \\
\text { yayın }\end{array}$ & $\mathbf{N}$ & $\begin{array}{l}\text { Sira } \\
\text { Toplamı }\end{array}$ & $\begin{array}{l}\text { Sira } \\
\text { Ortalaması }\end{array}$ & $\mathbf{U}$ & $\mathbf{z}$ & $\mathbf{p}$ \\
\hline & Yok & 55 & 1742.50 & 31.68 & \multirow{2}{*}{72.500} & \multirow{2}{*}{-2.693} & \multirow{2}{*}{.082} \\
\hline & $1-2$ & 5 & 87.50 & 17.50 & & & \\
\hline
\end{tabular}


Üniversitelerde İSG derslerine giren akademisyenlerin, İSG alanında kariyer yapma isteklerinin alanla ilgili yüksek lisans yapma ve doktora yapma durumuna göre anlamlı bir farklılığın olup olmadığı belirlenmek istendi. Yapılacak analiz türüne karar vermeden önce anket sorularına verilen cevap ortalamaları ile bağımsız değişkenler arasında homojen dağılımın olup olmadığı test edildi. Yapılan test sonuçlarında $\mathrm{p}<.05$ olduğundan homojenliğin sağlanmadığı görülmüştür. Bu durumda parametrik olmayan testlerden Mann Whitney U testiyle anlamlılığın var olup olmadığı test edilmiştir. İsg alanında kariyer yapma isteği- İSG alanında yüksek lisans yapma anlaml1lık testinde $U=250.000 ; z=-2.847 ; p=.004$ sonucu elde edilmiştir. $\mathrm{Bu}$ analiz sonucunda elde edilen $\mathrm{p}$ değeri 0.05 den küçük olduğu için anlamlı farklılık vardır. İSG alanında yüksek lisans yapmayanların İSG alanında yüksek lisans yapanlardan daha fazla İSG alanında kariyer yapmak istedikleri tespit edilmiştir. İSG alanında kariyer yapma isteği- İSG alanında doktora yapma analizinde $U=175.000 ; z=-1.800 ; p=.072$ sonucu elde edilmiştir ve $p>.05$ olduğundan anlamllık olmadığı belirlenmiş̧tir.

Yine akademisyenlerin İSG alanında kariyer yapma isteklerinin bu alanda yaptıkları SCI indeksli yayınlara bağlı olup olmadığını belirlemek için Mann Whitney $\mathrm{U}$ testi yapılmıştır. Analiz sonucunda $U=72.500 ; z=-2.693 ; p=.082$ sonucu elde edilmiştir ve $\mathrm{p}>.05$ olduğundan anlamlılık olmadı̆̆ı tespit edilmiştir.

Tablo 6: Kruskal-Wallis analiz sonuçları

\begin{tabular}{|c|c|c|c|c|c|c|c|}
\hline & $\begin{array}{l}\text { Diğer } \\
\text { indekslerde } \\
\text { taranan } \\
\text { yayın }\end{array}$ & $\mathbf{N}$ & Sira Ort. & sd & $X^{2}$ & $\mathbf{p}$ & $\begin{array}{c}\text { Anlamlı } \\
\text { fark }\end{array}$ \\
\hline \multirow{5}{*}{ 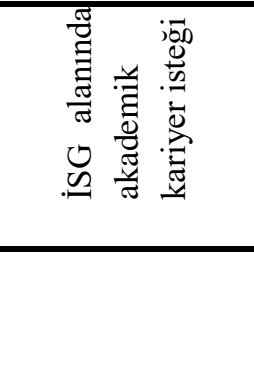 } & Yok & 40 & 32.75 & \multirow{4}{*}{3} & \multirow{4}{*}{4.613} & \multirow{4}{*}{.202} & \multirow{4}{*}{ Fark yok } \\
\hline & $1-3$ & 13 & 26.92 & & & & \\
\hline & $4-7$ & 5 & 20.00 & & & & \\
\hline & 8 ve üzeri & 2 & 35.00 & & & & \\
\hline & $\begin{array}{l}\text { Uluslararası } \\
\text { kitap/bölüm } \\
\text { yazarlığı }\end{array}$ & $\mathbf{N}$ & Sira Ort. & sd & $X^{2}$ & $\mathbf{p}$ & $\begin{array}{c}\text { Anlamlı } \\
\text { fark }\end{array}$ \\
\hline \multirow{4}{*}{ 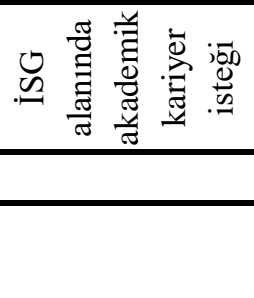 } & Yok & 50 & 32.00 & \multirow{3}{*}{2} & \multirow{3}{*}{4.250} & \multirow{3}{*}{.119} & \multirow{3}{*}{ Fark yok } \\
\hline & $1-3$ & 7 & 20.00 & & & & \\
\hline & $4-7$ & 3 & 30.00 & & & & \\
\hline & Ulusal yayın & $\mathbf{N}$ & Sira Ort. & sd & $\mathbf{X}^{2}$ & $\mathbf{p}$ & $\begin{array}{c}\text { Anlamlı } \\
\text { fark }\end{array}$ \\
\hline 䔍 & $\begin{array}{l}\text { Yok } \\
1-2\end{array}$ & $\begin{array}{l}34 \\
22\end{array}$ & $\begin{array}{l}35.00 \\
25.45\end{array}$ & 3 & 8.114 & .404 & Fark yok \\
\hline
\end{tabular}

Year 4/ 2020, Volume-4, Issue-4 | WWW.ispecjournal.org 


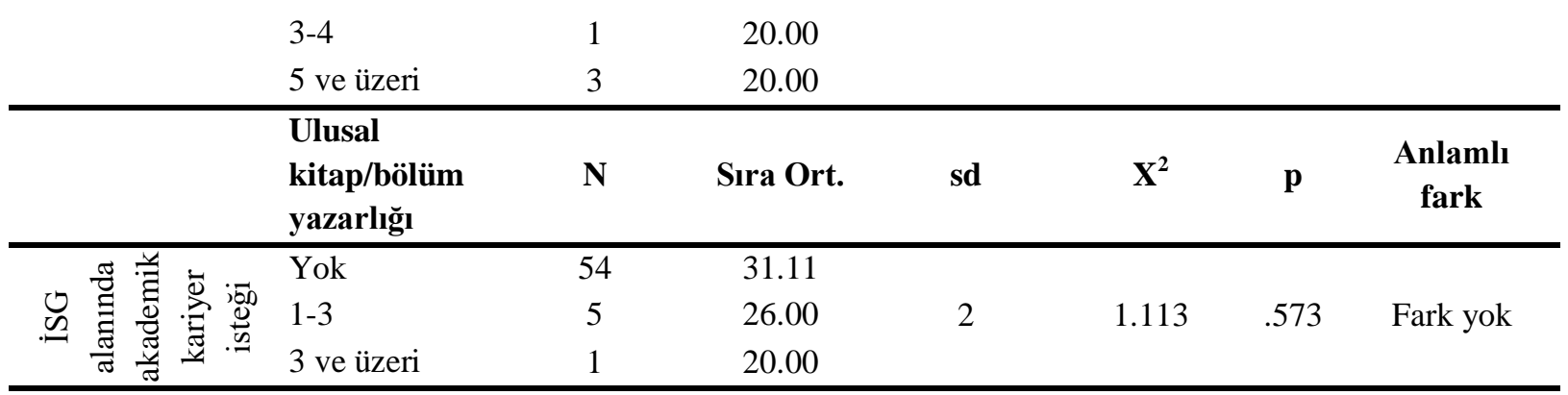

Akademisyenlerin İSG alanında kariyer yapma isteğinin İSG alanında diğer indekslerde taranan yayın sayısına, uluslararası kitap/bölüm yazarlık sayısına, ulusal yayın sayısına ve ulusal kitap/bölüm yazarlık sayısına bağlı olarak farklılaşıp farklılaşmadığını belirlemek istedik. Bağımsız değişkenlerin tümü homojen dağılım göstermediği için Kruskal-Wallis testi yapılarak anlamlılık testi yapılmıştır. Kruskal-Wallis testi sonucunda sırasıyla; $x^{2}(3, \mathrm{n}=60)=4.613 ; \quad p=.202 ; \quad x^{2}(2, \mathrm{n}=60)=4.250 ; \quad p=.119, \quad x^{2}(3, \mathrm{n}=60)=8.114 ; \quad p=.404$ ve $x^{2}(2, \mathrm{n}=60)=1.113 ; p=.573$ elde edilmiştir. Test sonuçlarında elde edilen $\mathrm{p}$ değerleri 0.05 ' den büyük olduğu için akademisyenlerin isg alanında kariyer yapma isteklerinin yapmış oldukları uluslararası indeksli yayın sayısı, ulusal ve uluslararası kitap/bölüm yazarlık sayısına, ulusal yayın sayısına bağlı olarak değişmediği belirlenmiştir.

\section{TARTIŞMA VE SONUÇ}

Çalışmadan elde edilen verilere göre akademsiyenlerin çoğunluğunun erkek olması akademsiyenlikte olsa bu mesleğin tehlikeli olmasından kadın akademisyenler tarafından daha az tercih edildiği, ankete katılanlarının büyük çoğunluğunun C sınıfı iş güvenliği uzmanlık belgesine sahip olmaları atanma kriterinin çoğunda iş güvenliği belge şartı aranmasından dolayı olabilir. Atama sonucu uzmanlık yapma eğilimleri düşük olduğundan $\mathrm{B}$ ve $\mathrm{A}$ iş güvenliği belgesine yükselme oranı düşüktür. Bazı üniversitelerde diğer bölümde hoca olupda eğitici belgesi sayesinde İş Sağlığı ve Güvenliğine geçiş yapılabilmektedir. Öğretim elemanlarının \% 60 a yakının başka bir uzmanlık alanında doktora dercesine sahip olduğunu görüyoruz. Hocaların yaklaşık olarak yarısının öğretim görevlisi olduğunu görüyoruz. İlk başlarda vakıf üniversitelerinde İSG programlarının açılmasına rağmen, sayısı bakımından devlet üniversitelerinin çok olması, yoğunluğun devlet üniversitelerine kaydırdığının göstergesidir. Lisans mezuniyetine göre sayıca mühendislerin daha sonra fen fakültesi mezunlarının olduğunu, alanında yetişmiş ve ataması yapılmış hocaların çok az olduğunu görüyoruz. Alanında yetişmiş hocaların sayısının artması zamanla ve teşvik ile artacaktır. 
Hocaların görev süresi bakımından çoğunluğunun 3 ile 5 yıl arasında görev yaptığını görüyoruz.

Akademik olarak incelediğimizde; İSG alanında yüksek lisans ve doktora mezunu olan hocaların az olduğunu, SCI 11 yayını olan hoca sayısının beş olduğunu, ululararası yayın, makale ve kitap bölümü olarak baktığımızda az sayıda akademisyenin çalışmasının olduğunu, çoğunluğun uzmanlık alanında çalışmalar yaptığını görüyoruz. Akademik çalışmasının az olmasına rağmen çoğunluğun İş Sağlığı ve Güvenliği alanında doçentlik unvanı almak istediğini görüyoruz. İSG bölümün hangi fakültede olmasını istersiniz diye sorulduğunda \%61 inin mühendislik faültesinde olsun dediğini görüyoruz. Bu sonucun çıkmasının sebebi; çoğu öğretim elemanlarının mezuniyetlerinin mühendis fakültesi olması ve İSG nin teknik bir bölüm olduğunu düşünmelerinden olabilir.

İSG alanında akademik kariyer yapma isteğinin, cinsiyet, medeni durum, eğitim düzeylerine bağlı olmadığını, görev yaptıkları üniversite göre değiştiğini görüyoruz. Bunun nedeni ise devlet üniversitelerinde çalışan hocaların daha istekli ve ileriye dönük planlarının daha fazla olduğundan olabilir. Araştırmaya katılan akademisyenlerin kariyer yapma isteğinin yaşa, sahip oldukları iş güvenliği uzmanlık belgesine, akademik unvana, görev yaptığı birim ve bölümde çalışma sürelerine bağlı olmadığını görüyoruz. İSG alanında yüksek lisans yapmayanların ve İSG alanında akademik çalışması olmayan hocaların daha istekli, yapanların ise daha isteksiz olduğunu görüyoruz.

6331 sayılı İş sağlığı ve Güvenliği yasasında görülen ertelemeler, iş kazası sonucu İSG uzmanın tutuklanması gibi durumlar ve yönetmeliklerin değişken olması sonucu öğrenci sayılarının değişebileceği, bunun devamında İSG bölümlerinin uzun vadede de nasıl konumda olacağı tahmin edilemediğinden akademisyenlerin bu alanda tam verimle çalışmasını etkileme durumu söz konusudur. Dolayısıyla bu durum da akademisyenlerin kendi uzmanlık alanlarından vazgeçmemeleride etken olabilir. İş Sağlığı ve Güvenliğine gerektiği önem verildiği sürece akademik ve teknik olarak daha gelişir. Akademisyenlerde bu alanda doçent ve prof ünvanları almak için daha çok çaba ve çalışmalar yapmaya başlayacaklardır. 


\section{KAYNAKLAR}

Aksoy, S. Çevik, B. Çakıcıer, N. (2013). “Gümüşova Meslek Yüksekokulu'nda İş̧ Güvenliği Bilincinin Belirlenmesi” Düzce Üniversitesi Bilim ve Teknoloji Dergisi, Cilt: 1, Say1: 1, Sayfa: 69-76.

Arslan, S. (2014). “İş Sağlığı ve Güvenliği Kanunu’na Göre İşverenin Genel Yükümlülükleri” Marmara Üniversitesi Hukuk Fakültesi Hukuk Araştırmaları Dergisi, Cilt: 20, Say1: 1, Sayfa: $767-808$.

Bıyıkcı, T, E. (2010). "İş Sağlığı Ve Güvenliğinin Sağlanmasında İş Güvenliği Uzmanlığı” Uludağ Üniversitesi Sosyal Bilimler Enstitüsü, Yüksek Lisans Tezi.

Ceylan, H. (2012). “Türkiye'deki İş Sağlığı Ve Güvenliği Eğitimi Sorunlar Ve Çözüm Önerileri” Electronic Journal of Vocational Colleges, Cilt: 2, Sayı: 2 Sayfa: 94-104.

Doğan, B. Yalçınkaya, C. Balcı, M., G. (2017). "Türkiye'de Mühendislik Fakültelerinde İş Sağlığı ve Güvenliğgi Eğitimi” Mühendis ve Makina, Cilt: 58, Sayı: 685, Sayfalar: $1-15 . \mathrm{s}$

Gür, B. Sezik, Y. (2020). "Mermer Fabrikalarında Çalışanların İş Sağlığı Ve Güvenliği Açısından Çalışma Koşullarının Belirlenmesi: Çorum İl Örneği, Ohs Academy Cilt: 3, Say1: 1, Sayfa: $47-52$.

Kılkış, İ. (2013). “İş Sağlığı ve Güvenliği’nde Yeni Dönem: 6331 Sayılı İş Sağlığı ve Güvenliği Kanunu (İSGK)” İş, Güç Endüstri İlişkileri Ve İnsan Kaynakları Dergisi, Uludağ Üniversitesi Cilt: 15, Sayı: 1, Sayfa: 17-41.

Orhan, S. (2014). "İş Güvenliği Uzmanlarının İş Güvencesi Sorunu” Hak İş Uluslararası Emek ve Toplum Dergi, Cilt: 3, Sayı: 6, Sayfa: 70 - 89.

Sivrikaya, O. (2016) “Türkiye'de Yükseköğretim Kurumlarında İş Sağlı̆̆ ve Güvenliği Eğitiminde Güncel Durum" Yükseköğretim ve Bilim Dergisi, Cilt: 6, Sayı: 2, Sayfa:151-162.

Şensögüt, C. (2018). “İş Güvenliği Kültürü ve Üniversiteler” Soma Meslek Yüksekokulu Teknik Bilimler Dergisi, Cilt:1, sayı:25. 